\title{
Development of fuzzy model for calculating the poverty of the region
}

\author{
Natalya Tovmasyan ${ }^{1, *}$, Dmitriy Nazarov ${ }^{1}$, Maria Ciurea $^{2}$ \\ ${ }^{1}$ Ural State University of Economics, Ekaterinburg 620144, Russia \\ ${ }^{2}$ University of Petroșani, Petroşani, Romania
}

\begin{abstract}
In the period of digitalization of the economy, informatization and automation of all business processes of any enterprise and the state as a whole is rapidly taking place. One of the global problems of any modern state is the problem of poverty associated with various economic aspects, including receiving benefits and compensations. The main group of the population with a high level of risk of falling into the group of the poor are pensioners, despite various social assistance programs. Social and economic support for the poor also reduces social tension in society. The main purpose of the research article is to build a fuzzy model for assessing the level of poverty in the region. The authors consider the essence of the concept of "poverty" and the existing methods for calculating the level of poverty in the region. FuzzyTech software was used to build and visualize the fuzzy model. In conclusion, the process of setting the fuzzy modeling problem and a description of its direct implementation by means of the selected software are described. The test of the developed fuzzy model for assessing the poverty level was carried out on the official indicators of the Kurgan region.
\end{abstract}

\section{Introduction}

The problem of poverty in the economy is determined by the following parameters: the number of people in need of assistance, the assessment of their material resources and the financial costs required to provide assistance. An important condition in the context of a budget deficit is the targeting of the assistance provided. In this regard, the problem arises of an adequate assessment of the poverty level of the household as a whole and of an individual, taking into account the incompleteness and / or uncertainty of the initial information (for example, the subjective and objective assessment of the poverty level of an individual can differ significantly). Standard statistical approaches are often incorrect, so we suggest using the fuzzy logic formalism to solve such problems.

The purpose of the scientific article is to develop a fuzzy model for assessing the level of poverty in the region using the example of the Kurgan region in the FuzzyTECH program.

\footnotetext{
*Corresponding author: nazarov_usue@mail.ru
} 


\section{Analysis of existing models for calculating poverty}

Three basic concepts of poverty in world practice are distinguished: absolute, relative, subjective.

The concept of absolute poverty is related to the concept of the poverty line. Poverty line is the level of disposable income, gross income or consumption below which a person is considered poor. Absolute poverty is often measured as the number of people or households whose consumption or income is below the poverty line. The poverty line as an indicator has a significant drawback: it does not take into account the number of households. Relative poverty measures set a relative poverty line and measure the income of the population to it. When the real incomes of the entire population grow, and their distribution does not change, the relative poverty remains the same. The concept of relative poverty is part of the concept of inequality. However, this does not mean that less equality always means less relative poverty, or vice versa.

Subjective poverty is a concept of poverty in which only the individual himself determines whether he is poor. There are many approaches to determining the level of subjective poverty: you can find out how many people consider themselves poor, or consider their friends to be poor. The subjective absolute poverty line can be identified based on public opinion, and then compared with it the income of the population.

Changes in the poverty rate are currently carried out using the deprivation approach. According to this approach, individuals are considered poor if their consumption does not correspond to the standard accepted in society or they do not have access to a certain set of goods and services, i.e. Poverty is determined not only by insufficient income or low consumption of essential goods and services, but also by low-quality food, inaccessibility of education and health services, lack of normal housing conditions, etc.

Measuring the level of poverty with the use of subjective and deprivation approaches allows us to conclude that the perception of poverty turns out to be significant for the population not just as being on the verge of physical survival. Poverty is a state when an individual cannot provide a dignified existence, taking into account the social norms and generally accepted standards prevailing in society.

The assessment of the poverty level until now is calculated from internal indicators and is based only on the income of the population. On February 15, 2019, the Prime Minister of the Russian Federation Dmitry Medvedev announced the need to change the approach to assessing the level of poverty. That is why we will consider a fuzzy approach to calculating this indicator, and we will take into account not only internal indicators of income, but also the current costs of a particular region, some external factors.

\section{Methodology for constructing a fuzzy model}

Due to the fact that we are considering an estimate of the level of poverty in the region, depending on internal and external factors, we will introduce two additional intermediate variables that will generalize the input variables to the weekend. The result of the immediate final output variable is based on intermediate variables that have their own set of fuzzy production rules.

Let's describe all the variables. The input parameters of the first intermediate variable $\mathrm{g} 1$ reflecting the assessment of the poverty level based on internal factors will be 5 linguistic variables: income level (x1), total income (x2), savings level (x3), share of spending on drugs (x4), share of expenditures for food (x5). The input parameters of the second intermediate variable g2, based on external factors, will be two linguistic variables: inflation in Russia (x6) and regional funding from the federal budget $(\mathrm{x} 7)$. 
All term sets of input linguistic variables X1-X7 are represented as sets T1-T7 = \{"Low", "Medium", "High"\}. As the term sets of the output intermediate variables G1 and G2, as well as the final output variable G, we will use the sets T8-T10 = \{"Low", "Medium", "High" $\}$. The terms of the variables X1 - X3 and X7 are estimated in monetary terms, and the terms of the sets X4 - X6 in percentage.

The income level (x1), for example, will be estimated from 0 to 50 thousand rubles, where 0 is the lowest income level, and 50 thousand is the highest. The terms of variables $\mathrm{x} 2$ and $\mathrm{x} 3$ are also estimated in rubles from 0 to 200 thousand, variables $\mathrm{x} 4, \mathrm{x} 5, \mathrm{x} 6$ as a percentage: from 0 to 30 , from 0 to 60 and from 0 to 8 . Terms of the variable responsible for financing the region from the federal budget countries $-\mathrm{x} 7$ will be estimated from 0 to 58 billion rubles; the terms of intermediate and output variables are from 0 to 1 , where values from 0 to 0.3 the degree of poverty risk is low, 0.4-06 - the degree of poverty risk is medium, 0.7-1 - the degree of poverty risk is high.

A table with the ranking of the input variables in a fuzzy form based on the official statistics for the Kurgan region is presented below (Table 1).

Table 1. Ranking of data for building a fuzzy model for assessing the level of poverty in a region on the example of the Kurgan region.

\begin{tabular}{|c|c|c|}
\hline Variable & Level & Parameters \\
\hline \multirow{3}{*}{ Income level (X1) [rub] } & Low & {$\left[\begin{array}{llllll}0 & 0 & 8000 & 12000]\end{array}\right.$} \\
\hline & Middle & {$\left[\begin{array}{llllll}8000 & 16000 & 16000 & 25000\end{array}\right.$} \\
\hline & High & [20000 250005000050000$]$ \\
\hline \multirow{3}{*}{$\begin{array}{l}\text { Total household income (X2) } \\
\text { [rub] }\end{array}$} & Low & {$\left[\begin{array}{lllll}0 & 0 & 10000 & 20000\end{array}\right]$} \\
\hline & Middle & [15000 200002000075000$]$ \\
\hline & High & {$[50000100000200000$} \\
\hline \multirow{3}{*}{ Savings level (X3) [rub] } & Low & {$\left[\begin{array}{lllll}0 & 0 & 70000 & 100000\end{array}\right]$} \\
\hline & Middle & $\begin{array}{c}{[70000100000100000} \\
150000]\end{array}$ \\
\hline & High & $\begin{array}{l}{\left[\begin{array}{l}125000150000200000 \\
200000]\end{array}\right.} \\
\end{array}$ \\
\hline \multirow{3}{*}{$\begin{array}{l}\text { Share of spending on drugs } \\
\text { (X4) [\%] }\end{array}$} & Low & {$\left[\begin{array}{llll}0 & 0 & 5 & 7,5\end{array}\right]$} \\
\hline & Middle & {$\left[\begin{array}{llll}5 & 10 & 10 & 15\end{array}\right]$} \\
\hline & High & {$\left[\begin{array}{lllll}12,5 & 15 & 30 & 30\end{array}\right]$} \\
\hline \multirow{3}{*}{$\begin{array}{l}\text { Share of expenditures for } \\
\text { food (X5) [\%] }\end{array}$} & Low & {$\left[\begin{array}{lllll}0 & 0 & 15 & 17,5\end{array}\right]$} \\
\hline & Middle & {$\left[\begin{array}{lllll}15 & 20 & 20 & 30\end{array}\right]$} \\
\hline & High & {$\left[\begin{array}{lllll}25 & 30 & 60 & 60\end{array}\right]$} \\
\hline \multirow{3}{*}{ Inflation (x6) [\%] } & Low & {$\left[\begin{array}{lllll}0 & 0 & 1,4 & 2\end{array}\right]$} \\
\hline & Middle & {$\left[\begin{array}{lllllll}1,5 & 3 & 3 & 4,5\end{array}\right]$} \\
\hline & High & {$\left[\begin{array}{llll}4 & 6 & 6 & 8\end{array}\right]$} \\
\hline \multirow{3}{*}{$\begin{array}{l}\text { Regional funding from the } \\
\text { federal budget }(\mathrm{x} 7) \text { [billion } \\
\text { rubles] }\end{array}$} & Low & {$\left[\begin{array}{llll}0 & 0 & 18 & 26\end{array}\right]$} \\
\hline & Middle & {$\left[\begin{array}{lllll}18 & 28 & 36 & 44\end{array}\right]$} \\
\hline & High & {$\left[\begin{array}{llllll}3 & 6 & 44 & 52 & 58\end{array}\right]$} \\
\hline
\end{tabular}

Based on the above ranking and knowledge of the area under consideration, we will compose a list of heuristic rules for the intermediate variables g1, g2 and the final output variable $\mathrm{g}$.

25 rules for the variable $\mathrm{g} 1$ were thought out. Some of them are described below:

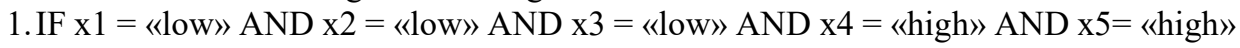
THEN g1 $=\langle$ high $»$

2. IF x1 $=$ «medium» AND x2 = «low» AND x3 = «high» AND x4= «low» AND x5= «low» THEN g1= «medium»

3. IF $x 1=\langle$ medium» AND x $=\langle$ medium» AND x3 = «medium» AND x4 $=\langle$ medium» AND $\times 5=\langle$ medium» THEN g1 $=\langle$ medium» 
4. IF $x 1=\langle$ high $»$ AND $x 2=\langle$ medium» AND x $3=\langle$ low» AND x4 $=$ «medium» AND $\mathrm{x} 5=\langle$ medium $»$ THEN g1 $=\langle$ medium $»$

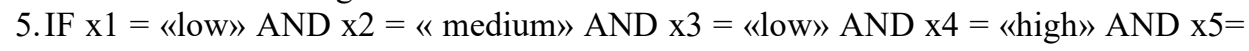
«high» THEN g1= «high»

6.IF $\mathrm{x} 1=\langle$ low» AND $\mathrm{x} 2=\langle$ medium» AND $\mathrm{x} 3=\langle$ low» AND $\mathrm{x} 4=\langle$ medium» AND $\mathrm{x} 5=$ «high» THEN g1 = «high»

7.IF $\mathrm{x} 1=$ «high» AND $\mathrm{x} 2=$ «high» AND x3 $=$ «high» AND x4 $=$ «low» AND $\mathrm{x} 5=\langle$ low $»$ THEN g1 $=\langle$ low $»$

8.IF $\mathrm{x} 1=$ =medium» AND $\mathrm{x} 2=$ 2 low» AND $\mathrm{x} 3=$ «medium» AND $\mathrm{x} 4=\langle$ medium $»$ AND $\mathrm{x} 5=\langle$ high $»$ THEN g1 $=\langle$ low $»$

9. IF $x 1=$ «high» AND x $2=$ «medium» AND x $3=$ «low» AND x4 = «high» AND x5= «high» THEN g1 = «high»

10. IF $x 1=$ «high» AND x $2=$ «medium» AND x3 = «high» AND x4 = «medium» AND $\times 5=\langle$ high» THEN g1 $=\langle$ medium»

The rules for the variable $\mathrm{g} 2$ are presented below:

1. IF x6 $=$ «low» AND x7 = «high», THEN g2 = «low»

2.IF $x 6=\langle$ low $»$ AND $\times 7=\langle$ medium», THEN g2 $=\langle$ low»

3. IF $x 6=\langle$ low $»$ AND $77=\langle$ low $»$, THEN g2 $=\langle$ medium»

4.IF x6 $=\langle$ medium» AND x7 $=\langle$ low», THEN g2 $=\langle$ high»

5. IF $\times 6=\langle$ medium» AND $\times 7=\langle$ medium», THEN g2 $=\langle$ medium»

6. IF $\times 6=\langle$ medium» AND $\times 7=\langle$ high $»$, THEN g2 $=\langle$ low»

7.IF x6 $=\langle$ high» AND x7 $=$ «low», THEN g2 = «high »

8. IF $x 6=\langle$ high» AND $\times 7=\langle$ medium», THEN g2 $=\langle$ medium»

9. IF $\times 6=$ 6 high» AND $\times 7=$ 7 high», THEN g2 = «medium»

List of rules for the output final variable $\mathrm{g}$ :

1. IF g1 $=\langle$ low $»$ AND g2 $=\langle$ low $»$, THEN g $=\langle$ low $»$

2. IF g1 $=\langle$ low $»$ AND g2 $=$ (medium», THEN g $=\langle$ low»

3. IF g1 = «low» AND g2 = «low», THEN g $=\langle$ medium »

4. IF $\mathrm{g} 1=\langle$ medium $»$ AND g2 $=\langle$ low», THEN g $=\langle$ low »

5. IF $\mathrm{g} 1=\langle$ medium $»$ AND $\mathrm{g} 2=\langle$ medium», THEN $\mathrm{g}=\langle$ medium»

6. IF $\mathrm{g} 1=$ « medium » AND g2 = «high», THEN g = « high »

7. IF g1 $=$ « high » AND g2 = « low », THEN g $=$ « medium »

8. IF $\mathrm{g} 1=$ « high » AND g2 $=$ « medium », THEN g $=\ll$ high »

9. IF $\mathrm{g} 1=\ll$ high $»$ AND g2 $=$ «high $»$, THEN g $=\ll$ high $»$.

\section{Results and discussion}

After the implementation of the model, we will analyze it, consider several cases of the operation of the resulting model based on specific indicators.

Consider a case based on the indicators of the Kurgan region, when the income level is 32 thousand rubles, the total household income is 50 thousand rubles, the level of savings is 70 thousand rubles, the share of expenses on drugs is $10 \%$, and the share of expenses on food $30 \%$ of the total budget, moreover, inflation in the country is $4.5 \%$ and financing of this region from the federal budget of the country is 44 billion rubles. Based on these indicators and on the basis of the resulting model, we can conclude that the assessment of the poverty level in the Kurgan region is at a low level and equal to 0.2923 (Figure 1). 


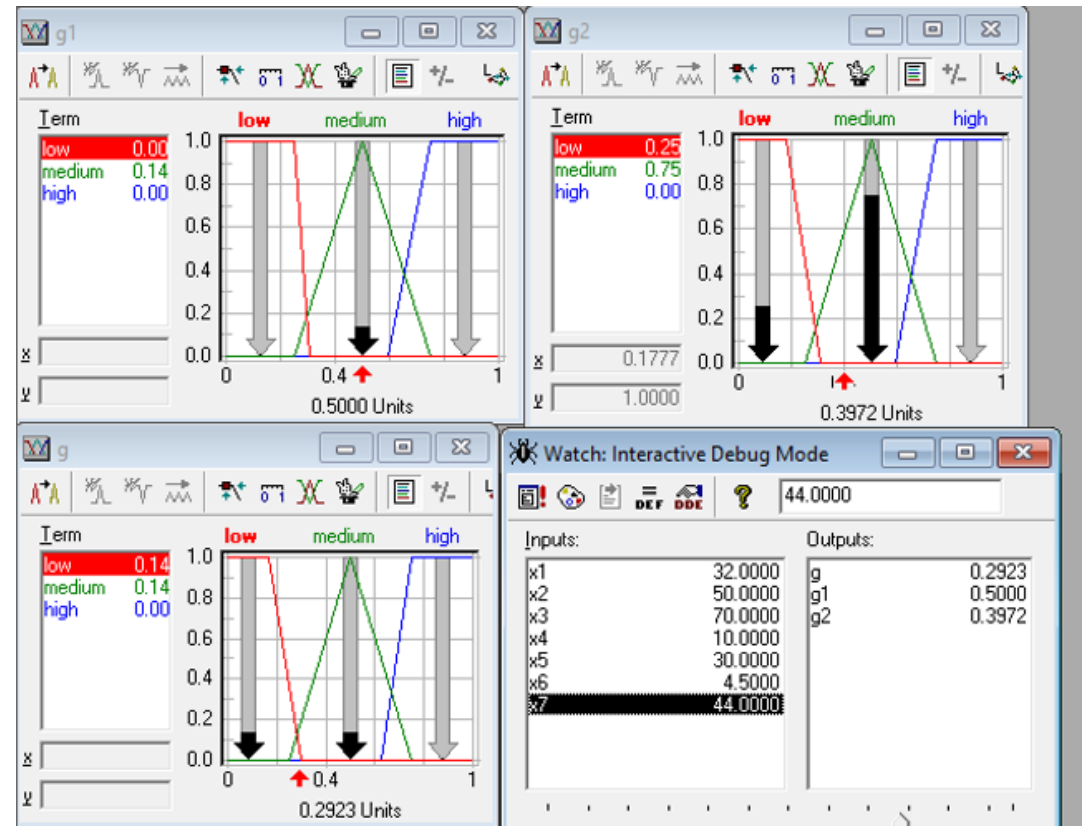

Fig. 1. Estimation of the poverty level based on the indicators of the Kurgan region.

For the final analysis of the developed fuzzy model, you can use the graphical window for viewing the surface of fuzzy inference on a plane and the graphical window for viewing the three-dimensional surface of the fuzzy inference (Figures 2-3). Figure 2 shows the influence of the input variables X3 and X7 on the final output variable g. Figure 3 shows the effect of variables $\mathrm{X} 2$ and $\mathrm{X} 6$ on the final output variable $\mathrm{g}$.

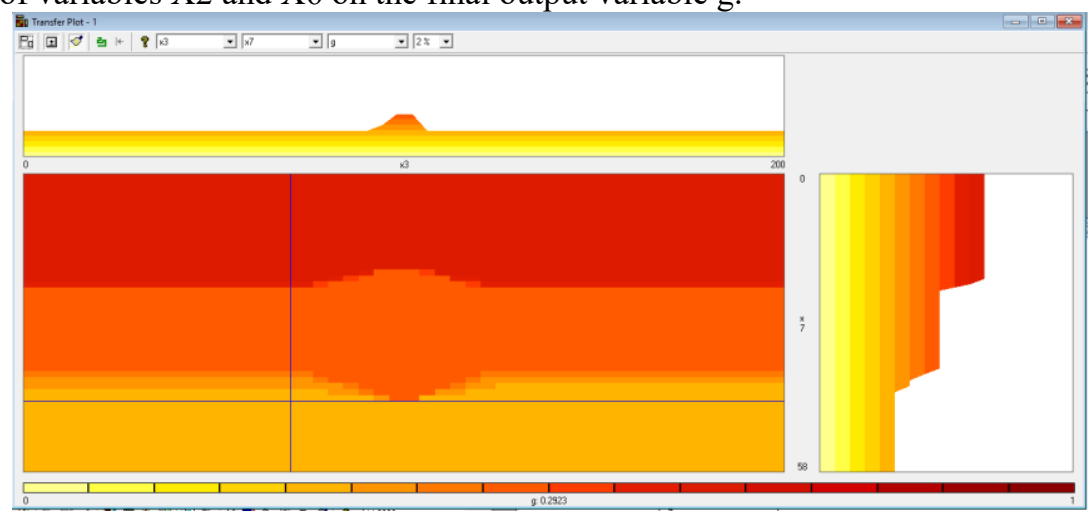

Fig. 2. Graphic window for viewing the surface of fuzzy inference. 


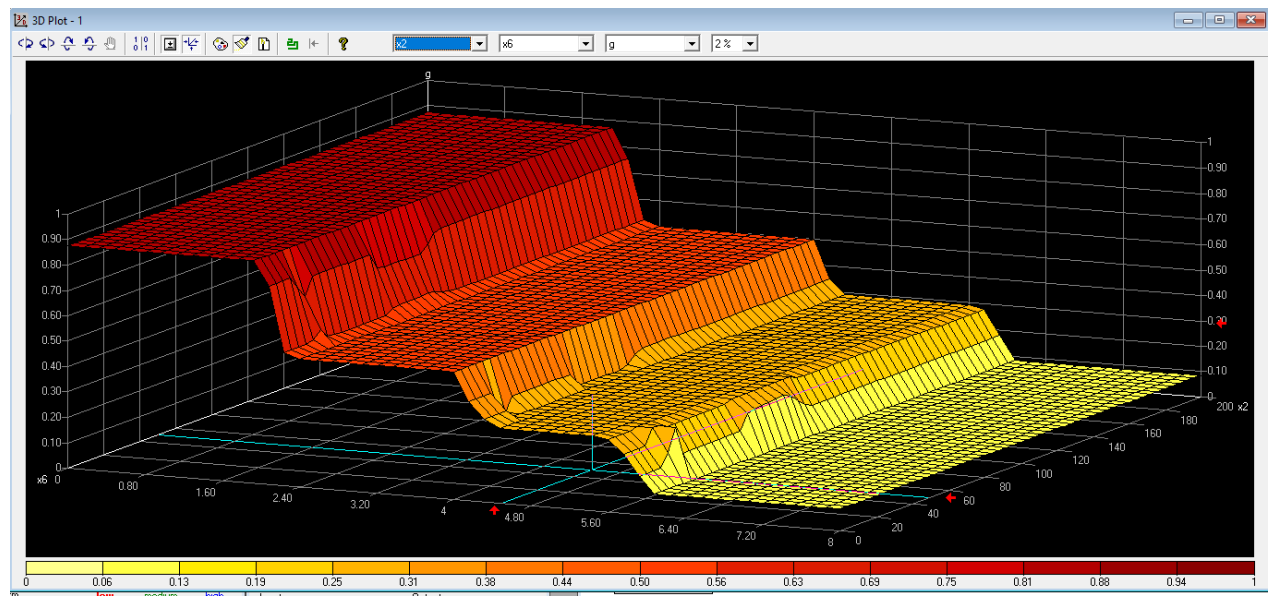

Fig. 3. Graphic window for viewing a three-dimensional surface.

These windows can also serve for general analysis of the correctness of a fuzzy model, allowing you to evaluate the effect of changing the values of the input fuzzy variables on the value of one of the output fuzzy variables.

Consider the following case where the performance is low. Based on these values, the poverty level of the region is on the border of the middle and high levels and equals 0.6875 (Figure 4).

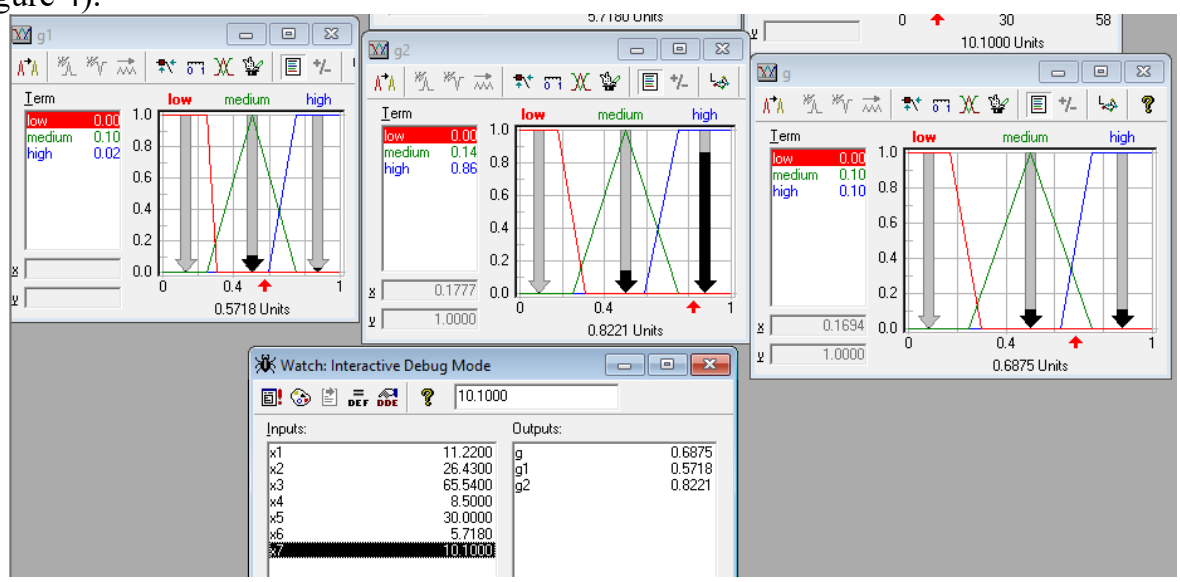

Fig. 4. Estimation of the poverty level at low rates.

Graphic windows of this case with the dependence of various indicators are presented in Figures 5-6. 


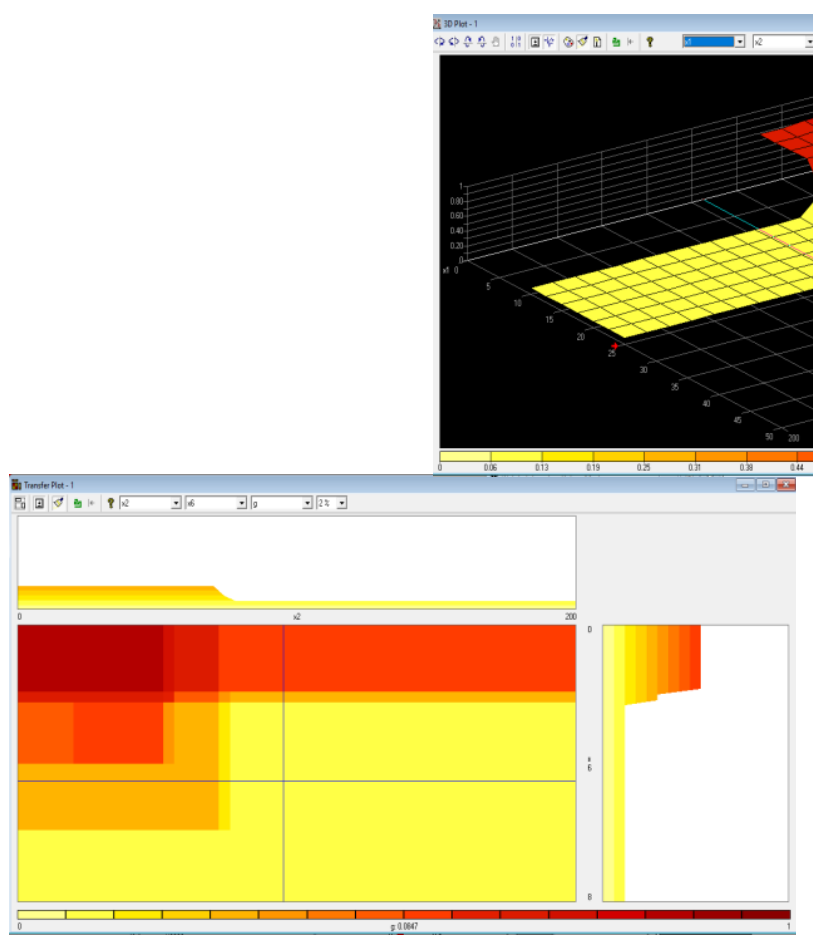

Fig. 5. Graphs of the influence of variables $X 2$ and $X 6$ on the variable $g$.
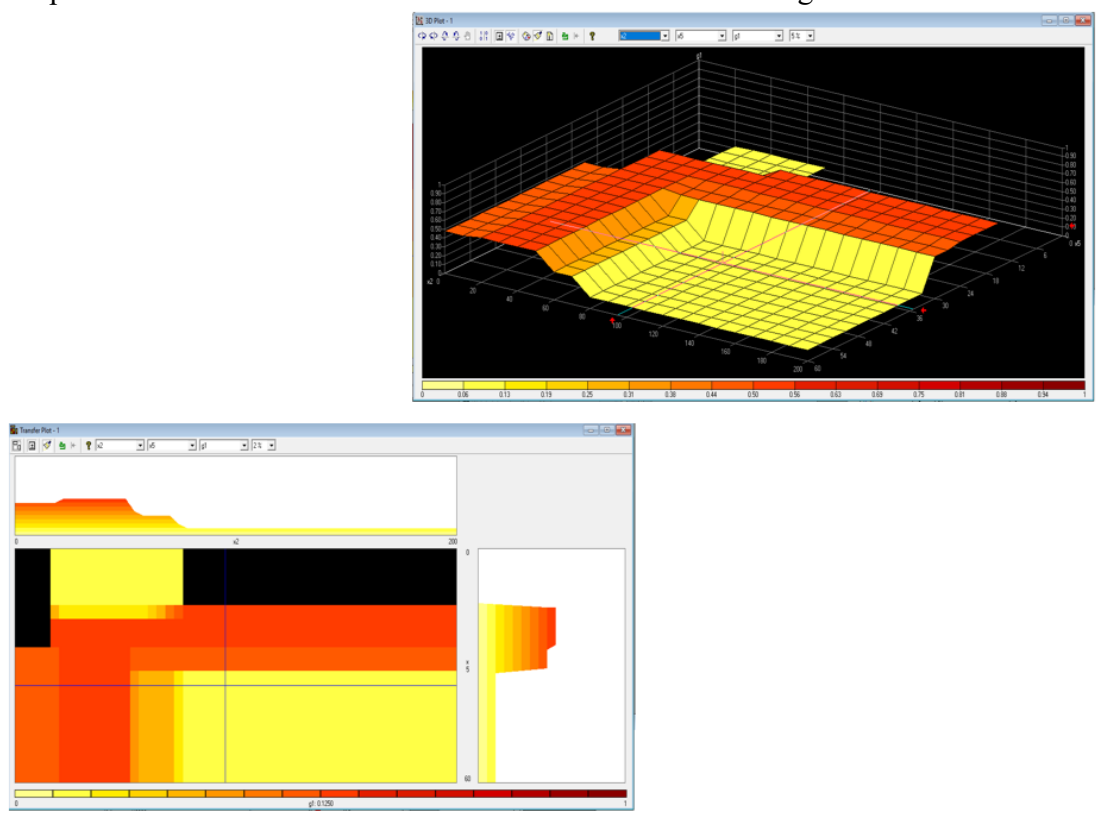

Fig. 6. Graphs of the influence of variables $\mathrm{X} 2$ and $\mathrm{X} 5$ on the variable $\mathrm{g} 1$. 


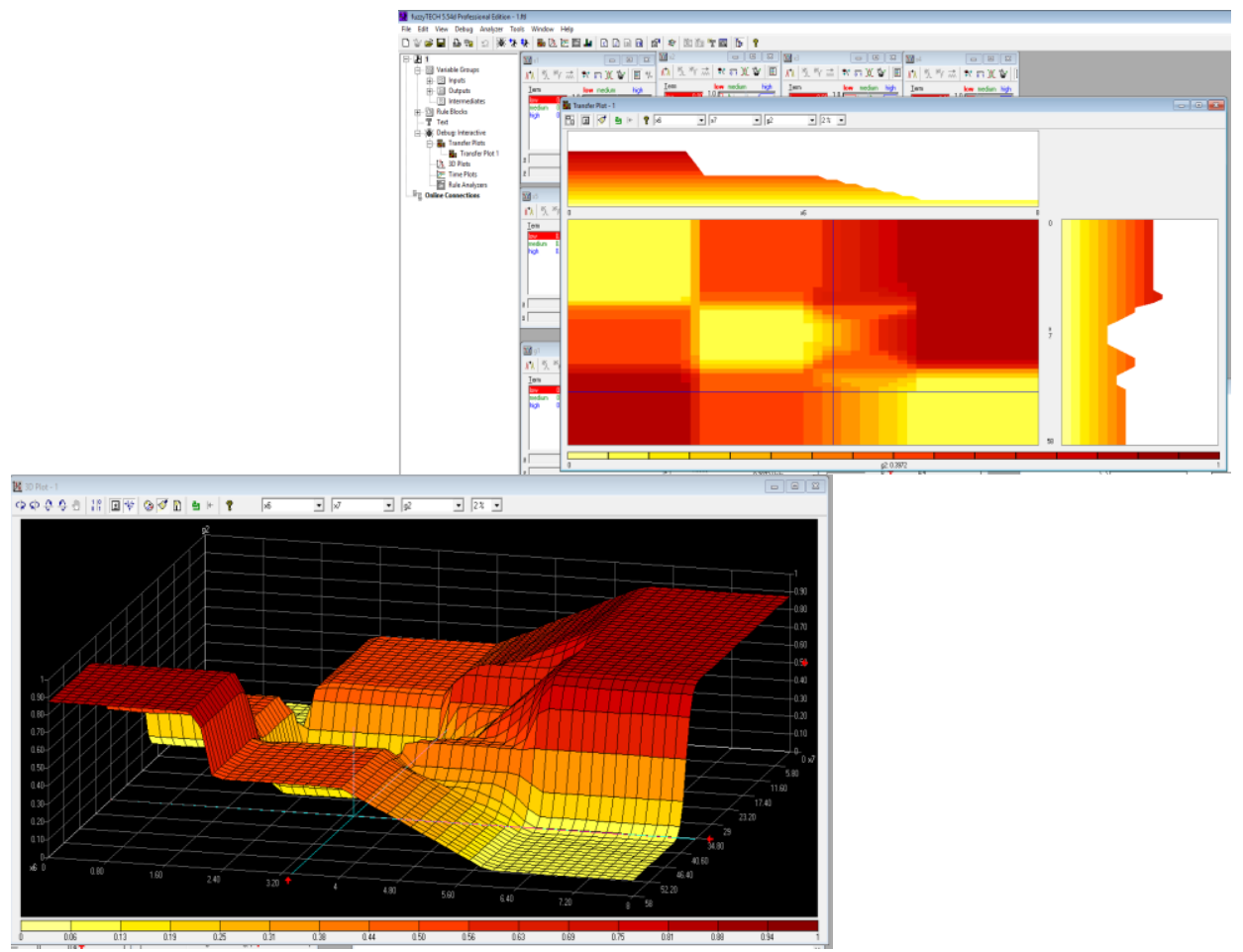

Fig. 7. Graphs of the influence of variables X6 and X7 on the variable g2.

\section{Conclusions}

Graphs reflect a complex picture of the dependence of the output variables on the input and are a convenient analysis tool. Within the framework of solving the problem of modeling the assessment of the level of poverty on the example of the Kurgan region, a fuzzy model was built. The model contains seven input variables, two intermediate variables, three rule blocks, and one final variable. Within the framework of the model, 43 rules were drawn up. When constructing intermediate and final variables, the defuzzification method was chosen - the center of the maximum.

The system was previously trained on specific rules. To test and analyze the resulting model for assessing the poverty level, not one, but five fuzzy models for assessing the level of poverty were designed for each region of the Ural Federal District. This was done on the basis of an important disadvantage of fuzzy modeling - the lack of a unified method for modeling systems, i.e. for each case, you have to redesign the fuzzy subroutine, determining step by step all the parameters, building a decision table.

The test of the developed fuzzy model for assessing the poverty level was carried out on the official indicators of the Kurgan region. The model showed that the estimate of the poverty level in this region is 0.2923 , which indicates a low risk to poverty. Fuzzy logic in many cases helps to implement complex models based on certain data in informal approaches, which allows improving the quality of object management and solving complex problems. 


\section{References}

1. N. Aghayi, S. Salehpour, RAIRO - Operations Research 54(6), 1775 (2020)

2. S. Ahmad, A. Ullah, K. Shah, S. Salahshour, A. Ahmadian, T. Ciano, Advances in Difference Equations (2020)

3. İ. Gölcük, Expert Systems with Applications 159, (2020)

4. M. G. Sharavana Kumar, V. R. Sarma Dhulipala, Measurement: J. of the Int. Measurement Confederation 166, (2020)

5. C. Wu, C. Lin, D. Barnes, Y. Zhang, J. of Cleaner Production 275, (2020)

6. M. Zhang, Y. Yang, H. Wang, L. Wang, Applied Mathematical Modelling 88, 142 (2020)

7. Y. Bai, G. He, H. Li, G. Wang, D. Zhou, IOP Conference Series: Earth and Environmental Science vol. 502(1), (2020)

8. M. Faulkner, L. C. Barker, S. N. Vigod, C. Dennis, H. K. Brown, J. of Epidemiology and Community Health 74(2),158 (2020)

9. M. L. Odland, C. Payne, M. D. Witham, M. J. Siedner, T. Bärnighausen, M. Bountogo, J. I. Davies, BMJ Global Health 5(3), (2020)

10. R. Osabohien, O. Matthew, P. Ohalete, E. Osabuohien, Social Indicators Research 151(2), 575 (2020)

11. A. U. Putra, H. R. V. Putro, L. S. Budiman, L. Adlina, R .F. Putri, IOP Conference Series: Earth and Environmental Science vol. 451(1), (2020)

12. E. Skoufias, A. Diamond, K. Vinha, M. Gill, M. R. Dellepiane, World Development, Elsevier vol. 129(C), (2020)

13. N. Meenakshi, P. Nagar, IJRASET 3(10), 260 (2015)

14. L. A. Zadeh, Fuzzy sets Information and Control 8, 338 (1965)

15. E. H. Mamdani, IEEE Transactions on Computers 26(12), 1182 (1997)

16. G. J. Klirm, B. Yuan, Fuzzy Sets and Fuzzy Logic: Theory and Applications (NJ: Prentice-Hall) p. 592 (1995) 